\title{
Localized Trust - The Semiotics in Culture and E-Culture
}

\author{
Tim French, Marc Conrad, Hussein Shaaban \\ University of Bedfordshire, United Kingdom
}

\begin{abstract}
Intangible trust perceptions have been shown to form an important part of the User Experience (UX) in relation to various $B 2 C$ (Business-to-Customer) contexts of use. The extant literature appears somewhat immature in relation to intangible trust and UX models from a "non-Western" perspective. Indeed it appears from our recent e-Banking audit using a novel cross-cultural expert evaluation instrument that too often "Western" Banks (such as Deutsche Bank) rely on perceptions of "Eastern" cultures viewed through a lens that relies on stereotypical images, signs and Western style templates. After identifying how trust and semiotics work considering the case of Zanzibar we compare two contrasting e-Bank site localization design paradigms: namely that of Deutsche Bank and HSBC with respect to two target audiences: namely China and Taiwan. The findings of the e-Culture audit are aligned to the ubiquitous set of cultural dimensions first defined by Geert Hofstede. This alignment appears to show that the "Western" stereotypical paradigm is not in alignment with either Hofstede's Individualism/Collectivism metric nor with normative semiotic signs that reflect vibrant local urban street cultures. We go on to suggest that the use of card-sorting may speculatively be used to better engender localized sites that are aligned to local target.
\end{abstract}

\section{Introduction}

Intangible trust perceptions of B2C users as part of their UX have been extensively researched in the "West". While a full literature review would be out of the scope of this paper much of the relevant work can be found in [1]. Indeed it is well known that trust relationships between individuals differ fundamentally when we compare "West" and "East". For example [2] have shown how Guanxi trust building influences every aspect of trust relations in China. The same could be equally said of Taiwan, Japan and Korea. Despite this fundamental difference wherein individual notions of identity are fundamentally family centric and collectivist in Southeast Asia as compared to more individualist centric "Western" societies, there has been little attempt to model these fundamental differences in relation to site localisation. These issues are not only restricted to this East / West cultural divide but may become more complex in other environments that do not so easily fall into these categories, as we will demonstrate on the example of Zanzibar.

Nevertheless one of the problems is that localization often relies on the use of "Western" templates or use of local witnesses but is not based on any underlying taxonomy of signs or theoretical paradigm such as semiotics. After highlighting and emphasizing the need for further investigation following a case study in the African state of Zanzibar we will then present the results of applying a novel set of cross-cultural heuristics to two alternative e-Banking sites. From applying the instrument, sign taxonomy emerges that seeks to quantify the use of cultural and visual attractors used. We also align the results of the audit to Hofstede's cultural dimensions which though often criticized form the basis of much cross-cultural studies. Using the results of this "proof-of-concept"" study we go on to propose a "quick-and-dirty" method that seeks to leverage card sorts so as to enable a set of early prototype designs to converge on a set of cultural characteristics that matches both Hofstede's dimensions and local audience expectations.

\section{Cultural and Organizational Semiotics}

\subsection{Organizational Semiotics}

Organisational semiotics is the study of organisations using sign systems as communication tools between human beings, information and technology within a social reality [3]. Organisational semiotics defines an organisation as a social system or a social structure in which people behave in an organised manner by conforming to a certain system of social norms. Norms make members of organisation behave, think, judge and view the world [4]. To be more specific, norms are classified into six levels which are social world, pragmatics, semantics, syntactic, empirics and physical world [5].

\section{Social World}

Here is where social norms that influence culture are interpreted by individuals. Norms are categorised into perceptual which are accepted ways of viewing the world, cognitive which are measured beliefs and 
knowledge possessed by a community, evaluative which guide the community towards common courses and behavioural which control members so that they behave in an correct manner [3]. The culture of the organisation is important because signs are used upon the culture in which they belong. Beliefs, expectations, functions, commitment, contract, law and culture are part of this social world [3].

\section{Pragmatics}

Here is where one can understand the purpose and relationship among cultural behaviours. Organisations with pragmatic problems are in a state of confusion. The semiotic framework includes on this level intentions, communications, conversations and negotiations [3].

\section{Semantics}

Here is where one can understand the meaning of cultural behaviour. Employees from different backgrounds need to understand each other in order to work together. Semantic problems that an organisation may encounter are a new market notion, and a new organisational notion among others. Meaning, propositions, validity, truth, signification and denotations are part of this level [3].

\section{Syntactics}

Here is where one can compose cultural behaviour from simple behaviours. Culture can be coded following a certain design. In an organisational environment activities are often in disorder and issues of interest establish how to bring order and structure in the organisation. According to the semiotic framework formal structure, language, logic, data, records deduction, software and files are on this level [3].

\section{Empirics}

Here is where culture meets technology. Physical phenomena are organised into predictable and recognised patterns. In an organisation events are loaded with randomness. Business matters are managed in uncertainty. On this level are pattern, variety, noise, entropy, channel capacity, redundancy, efficiency and codes [3].

\section{Physical World}

Here is where the culture meets the hardware. Physical issues alarm the media for storing and transporting signals. Business issues occur due to the economics of the physical resources. On this level are signals, traces, physical distinctions, hardware, component density, speed and economics [3].

\subsection{Cultural Semiotics}

In contrast to organizational semiotics, as discussed in the previous section, cultural semiotics is the study of culture through the use of signs. According to [6], a sign is composed of expression and content. Signs are tools that facilitate social interactions [6]. A sign is a medium for humans to understand things. People communicate significance, create meanings, and convey thoughts and sentiments via signs or sign systems. Signs and norms cannot be separated [4]. Culture or subculture is defined by shared norm. Hofstede [7] measures national culture by using five dimensions which are power distance, uncertainty avoidance, individualism, masculinity versus femininity and long-term versus short-term orientation.

\subsection{Relationship between Cultural and Organizational Semiotics}

Table 1. Mapping between organizational semiotics and cultural semiotics

\begin{tabular}{|c|c|c|c|c|c|}
\hline \multirow{2}{*}{$\begin{array}{l}\text { Organi- } \\
\text { sational } \\
\text { Semiotics }\end{array}$} & \multicolumn{5}{|c|}{ Cultural Semiotics } \\
\hline & PDI & IDV & UAI & MAS & LTO \\
\hline $\begin{array}{l}\text { Social } \\
\text { world }\end{array}$ & $\mathrm{X}$ & $\mathrm{x}$ & $\mathrm{x}$ & $\mathrm{x}$ & $\mathrm{x}$ \\
\hline $\begin{array}{l}\text { Prag- } \\
\text { matics }\end{array}$ & $\mathrm{x}$ & $\mathrm{x}$ & $\mathrm{x}$ & $\mathrm{x}$ & $\mathrm{X}$ \\
\hline Semantics & $\mathrm{X}$ & $\mathrm{X}$ & $\mathrm{X}$ & $\mathrm{X}$ & $\mathrm{X}$ \\
\hline Syntactics & $\mathrm{x}$ & & $\mathrm{x}$ & & $\mathrm{X}$ \\
\hline Empirics & $\mathrm{x}$ & & $\mathrm{x}$ & & \\
\hline $\begin{array}{l}\text { Physical } \\
\text { World }\end{array}$ & $\mathrm{x}$ & & $\mathrm{X}$ & & \\
\hline
\end{tabular}

Table 1 shows a basic mapping between cultural semiotics and the organisational semiotics that maps Stamper's framework [5] against Hofstede's cultural taxonomy [7]. All five cultural dimensions map onto the social world, pragmatics, and semantics levels: for example, within a culture with high Masculinity Index (MAS) a contract signed by a male member will have more weight while a culture with low MAS will show no gender bias. Similarly the Power Distance Index (PDI) and Individualism Index (IDV) impact how communication from 'leaders' will be perceived by ordinary citizens. Long Tern Orientation Index (LTO) and Uncertainty Avoidance Index (UAI), for instance determine how policies should be designed to achieve general acceptance.

Only PDI and UAI are mapped to all of the three lower levels, syntactics, empirics and physical world. For example, in cultures with high PDI leaders may use a different language compared to ordinary citizens; or the PDI - on the empirical level determines the width of a social gap in the use of the latest technology such as broadband. A high UAI within a culture, for example, might slow down 
modernisation ("physical world") due to resistance to change.

On the syntactic level the UAI may determine how formal specific interaction between the various stakeholders within Information Security needs to be. The relationship between cultural and organizational semiotics provides the context in which this study operates.

\section{Trust Formation in Zanzibar}

To provide a clearer picture of the aims of this paper we provide a case study that illustrates the ubiquity of the use of trust factors - be it knowingly or as a conscious decision by the web designer or without reflection and only influenced by the cultural organizational and societal context in which the designer operates.

Zanzibar is an archipelago consisting of two main Islands of Zanzibar and Pemba. It is a semiautonomous part of the United Republic of Tanzania. The House of Representatives is responsible for passing new laws in Zanzibar. Members of the House of Representatives come from two major political parties. Since multi-party democracy started in 1992 elections have been marred with violence and fraud accusations.

The vast majority of Zanzibaris are Muslims but the government of Zanzibar is ruled by secular laws. Ethnic groups in Zanzibar are Africans, Indians, Arabs and Europeans. The national culture of Zanzibar is based on Swahili culture [8]. The majority of small business transactions are conducted without written contracts. Also, favouritism exists in the Zanzibar society based on blood relation, marriage, region of birth, area of residency and political affiliation. According to Hofstede's national culture index, Zanzibar as part of East Africa has moderate power distance, low individualism, moderate masculinity, moderate uncertainty avoidance and low long-time orientation [9]. In 2012 Zanzibar planned to adopt an e-government system [10].

In Zanzibar's society people who participate in community events such as funerals and weddings, and belong to neighborhood Maskanis - a kind of social club where neighbors socialize - are more likely to be trusted in the community than others. Members of Maskanis are not documented and free to join. Since the introduction of multi-party democracy in 1995 the Maskanis have been involved with the formation of political opinion and now usual belongs to political parties. However, people who belong to political neutral Maskanis are more trusted then others. In addition, older people, people in power and religious leaders are usually trusted more. Similarly people who dress by following the Islamic code are more trusted then others. Also, Zanzibaris who pray regularly are more trusted than others. In general it can be stated that the Government's own infrastructure as well as Mosques are more trusted in Zanzibar than others institutions such as private or commercial. In business, Zanzibaris trust a straightforward approach.

In the terms of Hofstede, Zanzibar is a family centric society with low individualism.

Given this societal context we illustrate this point by considering six case studies where these trust signs are used to enhance the 'trustworthiness' of an Zanzibar website.

\subsection{Zanzibar Social Security Fund}

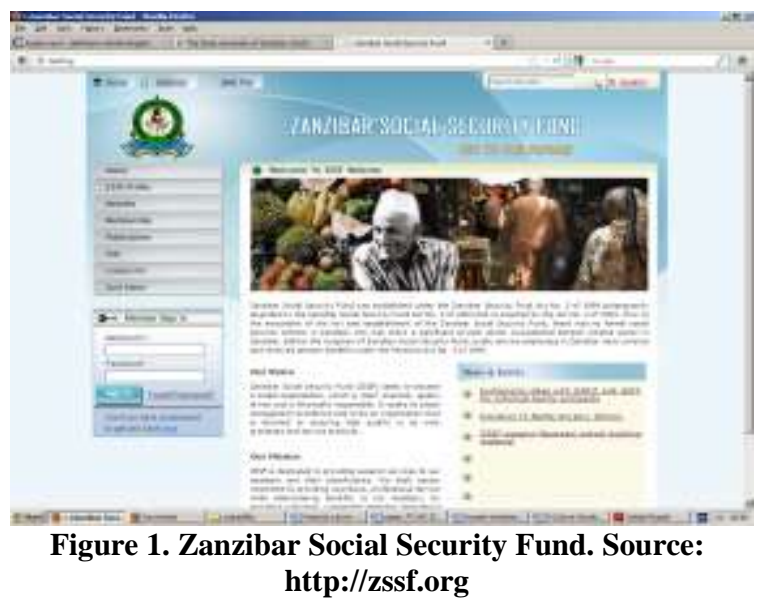

Fig. 1 shows prominently an image of old 'local' people dressed following the Islamic code, shopping in a local market. An impression of trust is formed through the association with respect given to older people. Stereotypically the Pension Fund is associated with 'old people'.

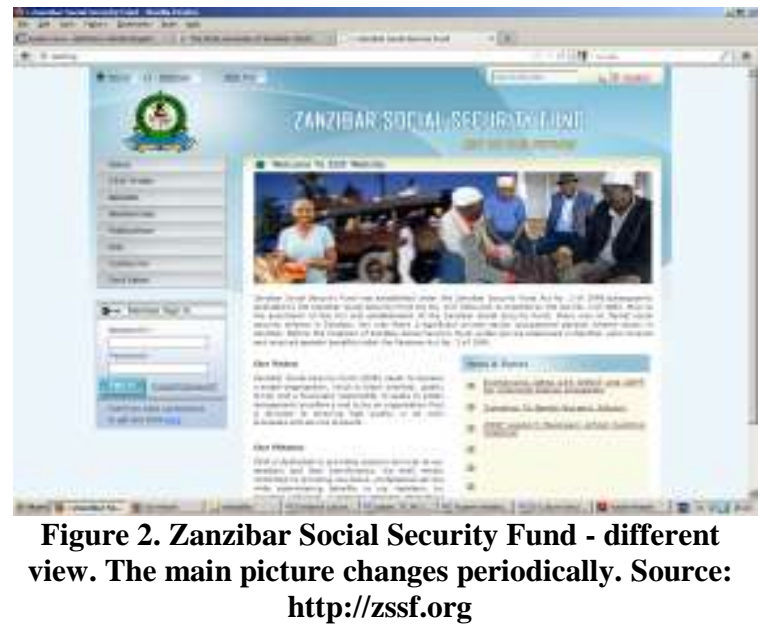

This is similarly visible in Figure 2 which shows a screenshot of the same site with a different image (the site loops through a couple of these images - all following a similar theme). Here we see a stereotypical image of old people in a Maskani on the right side plus a smiling old lady on the left hand 
side of the image. Again trust is formed through the association with respect given to older people. Interestingly, in Fig. 2 it is visible even to the untrained eye that the image has been edited together from at least two or three images. However this obvious 'cheat on reality' apparently was not considered by the authors of the website as having a deteriorating effect on trust formation. Website: http://zssf.org/; accessed: $7^{\text {th }}$ September 2012.

\subsection{Zanzibar Revenue Board}

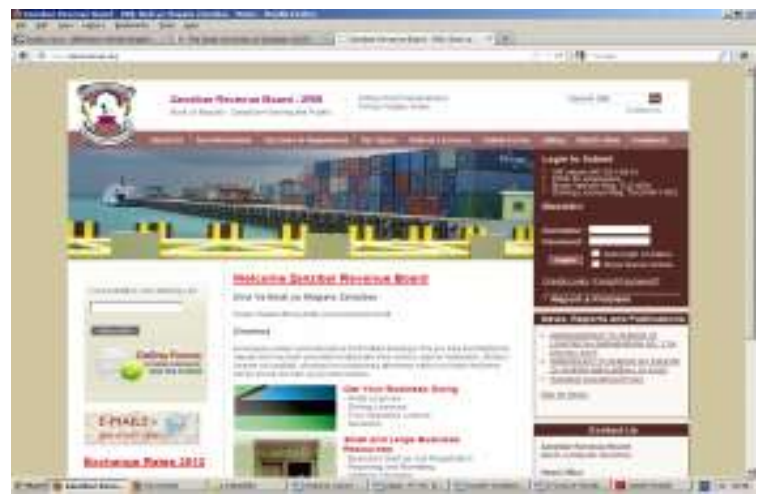

Figure 3. Zanzibar Revenue Board with image of port on the site. Source: http://www.zanrevenue.org

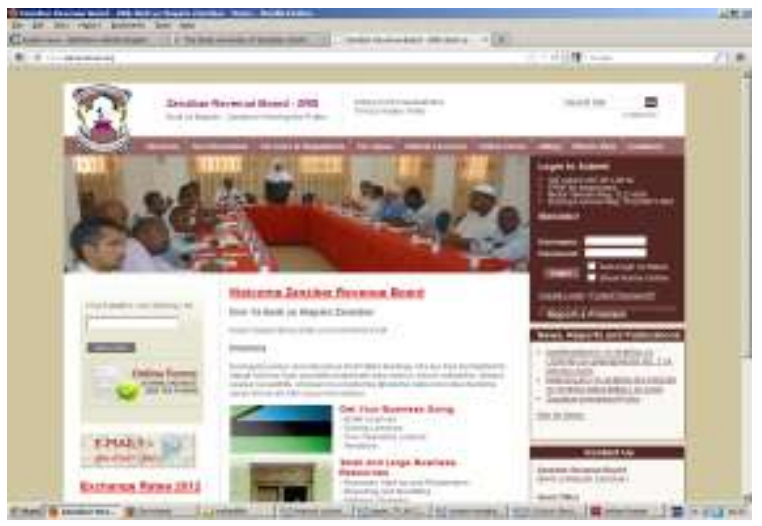

Figure 4. Zanzibar Revenue Board with image of meeting on the site.

Source: http://www.zanrevenue.org.

Fig.3 and Fig. 4 show two different views of the website of the Zanzibar Revenue Board - again the website loops through a variety of images following similar themes. In Fig. 3 trust is formed with images of a local port - in Fig. 4 we see in a meeting of employees. In the middle of the site - in both screens - the Zanzibar flag is visible. An impression of trust is here associated with respect to authority but to also demonstrate the Revenue Board as part of society and business. Website: http://www.zanrevenue.org/; accessed: $7^{\text {th }}$ September 2012.

\subsection{The People's Bank of Zanzibar Ltd}

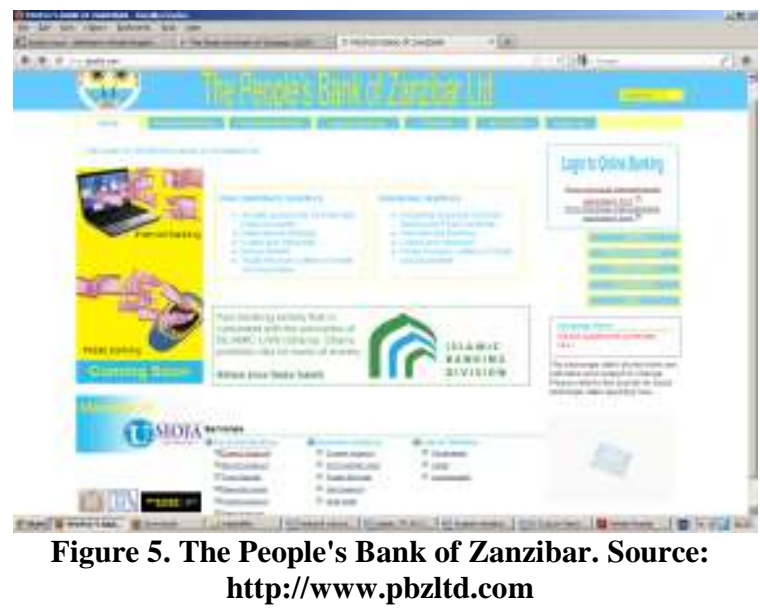

In Fig. 5 trust is formed by images of money and technology to be used to transfer money - a computer and a mobile phone. Prominently in the middle is the reassurance that the banking activities follow the Sharia law illustrated by a stylized graphic of a mosque. Trust is formed by the linkage between religion, modern technology and money. Interestingly none of the 'Western' or 'Eastern' banking sites we consider in the subsequent sections features actual ' real' money, i.e. bank notes or coins. Website: http://www.pbzltd.com; accessed: $7^{\text {th }}$ September 2012.

\subsection{The State University of Zanzibar}

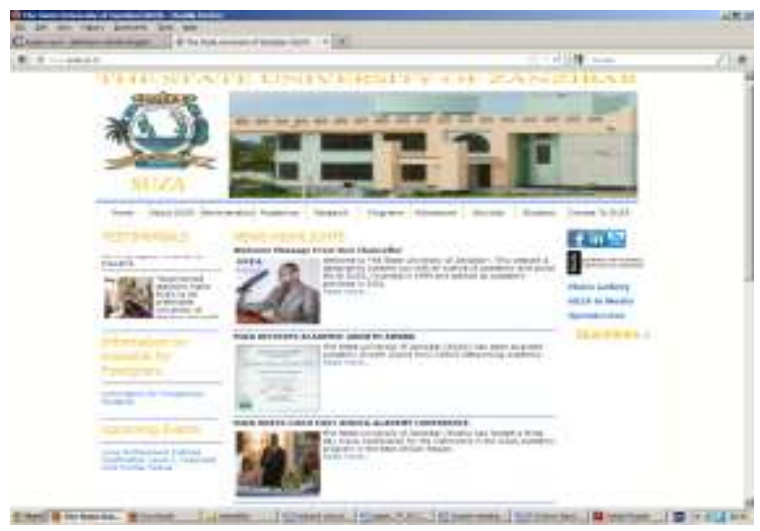

Figure 6. Screenshot of website of the State University of Zanzibar. Source: http://www.suza.ac.tz 


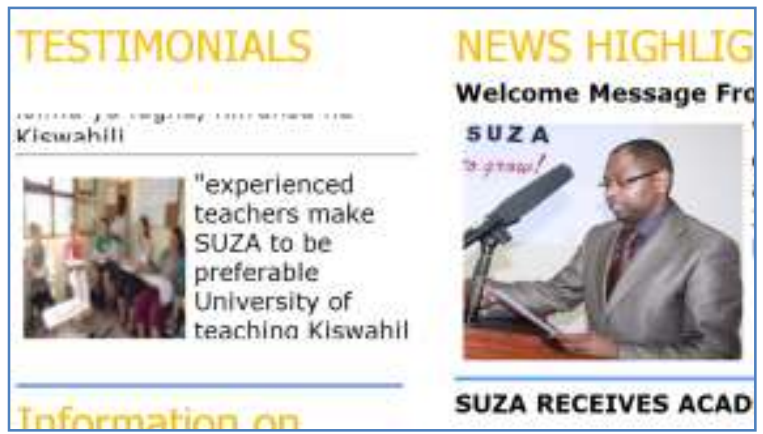

Figure 7. Detail of website of the State University of Zanzibar. Source: http://www.suza.ac.tz

In Fig. 6 we see images of a building, the vice chancellor as well as foreign students and their testimonials (see detail in Fig. 7). An impression of trust is formed here by association with continuity ('building'), authority (vice chancellor) and foreign witnesses. Website: http://www.suza.ac.tz/; accessed $7^{\text {th }}$ September 2012 .

\section{Localization of E-Banking}

In order to facilitate a systematic comparison across countries screenshots have been made of HSBC and Deutsche Bank e-banking sites for a variety of countries on a given date and "frozen" on a dedicated web site [11] for further analysis. The screenshots have been further contextualized by correlating them with Hofstede's cultural "fingerprint".

From this data we selected two e-Banking sites that are designed for two target local audiences: namely China and Taiwan. We applied a crosscultural heuristic evaluation instrument first developed in 2002 for commercial localization work by Optimum Web Ltd., and further adapted this for the purposes of e-Banking site audit. That is, a detailed qualitative evaluation and analysis structured around a set of expert cross-cultural heuristics was used for each site. These heuristics have been developed from leading edge best industrial practice as well as from timely and relevant research sources. The following ten heuristics are used to generate qualitative feedback:
(a) Metaphor(s) used
(b) Language(s) used
(c) Branding and Trust Issues
(d) Colours used
(e) Web-site Attractors
(f) Aesthetic Design and Appeal
(g) Navigation model
(h) Formats (date, time, special character sets)
(i) Customer Relationship Management (CRM)
(j) Miscellaneous Contextual Features of the Visual Design

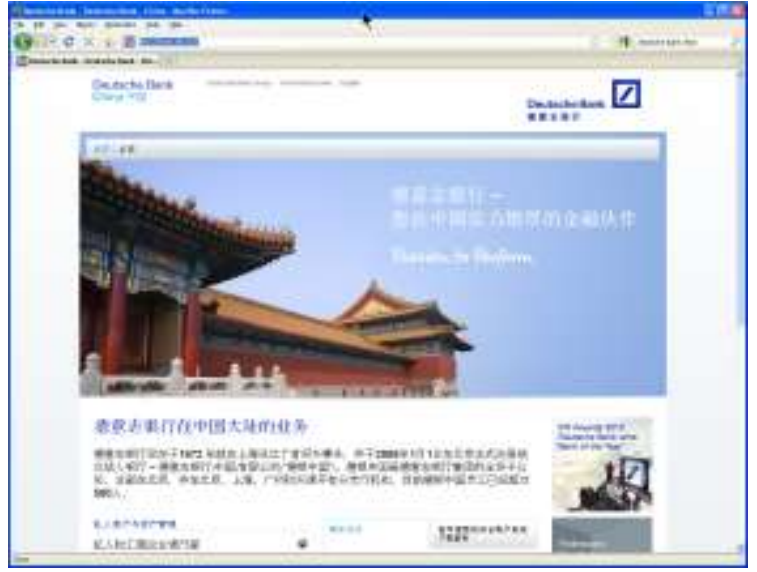

Figure 8. Deutsche Bank, China [3]

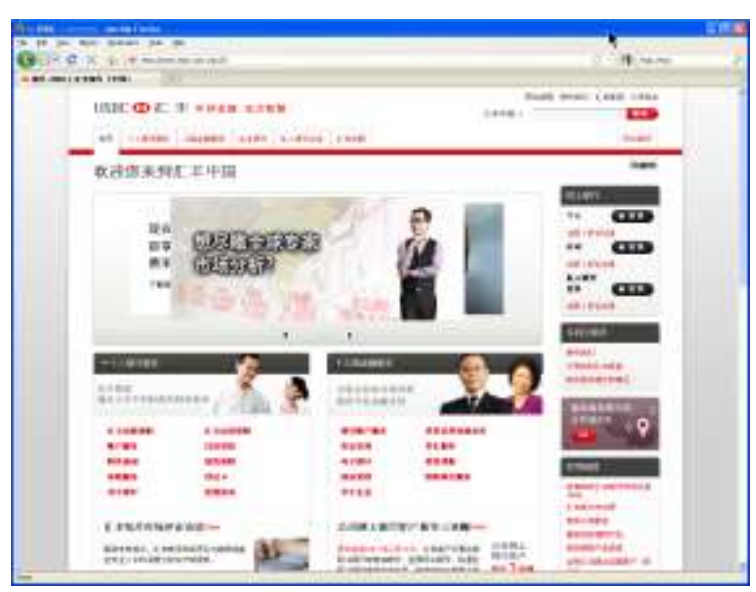

Figure 9. HSBC, China [3]

The results are presented in summative form below, together with a more detailed examination of the two sites from the perspective of "cultural attractors" (i.e. Heuristic (e) above) present in the more richly vibrant HSBC sites. These appear to reflect a more accurate picture of local cultural norms (for China and Taiwan!) and also Hofstede's collectivist dimensions

- Deutsche Bank China (Fig. 8): Prominent image of Tiananmen Square building (part of $G u$ Gong, The Forbidden City). Impression of trust formed through association with respect given to authorities. Textual content gives detailed descriptions. Presents a "stereotypical" (Western) image of mainland China.

- HSBC China (Fig. 9): Trust through association with financial data. Prominent use of human images used mainly in pairs. Multiple goal initiators present on homepage level.

- Deutsche Bank Taiwan (Fig. 10): Trust in hierarchical symbols (such as the famous 12-1 Tower, one of the World's tallest 
buildings located in downtown Taipei. Reflects "Western" stereotypical images rather than human centric collectivist urban shopping culture.

- HSBC Taiwan (Fig. 11): Use of traditional (New Year lantern festival) visual iconography, together with human forms used in groups reinforces traditional values and collectivist nature of society explicitly. Rich multiple links on the home-page create a rich set of choices for users and give the site a visual vibrancy reminiscent of "street" signage in urban settings, such as night markets.

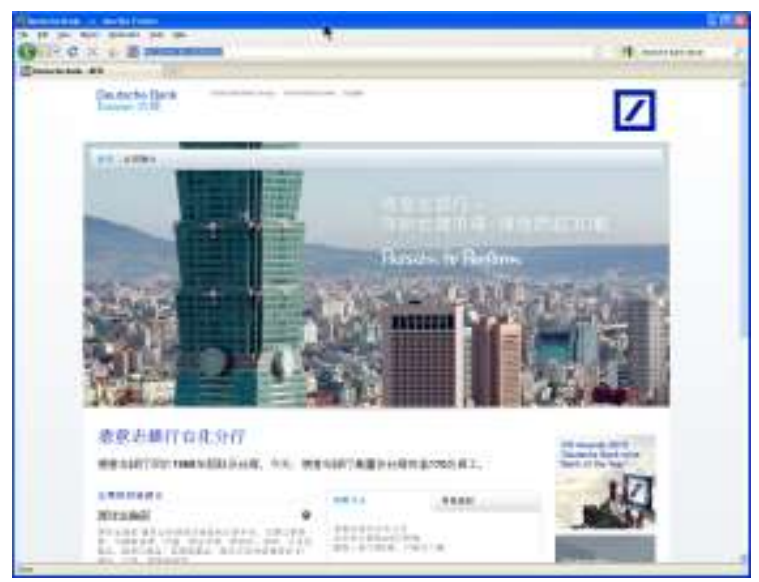

Figure 10. Deutsche Bank, Taiwan [3]

In respect of the latter site (HSBC Taiwan) further deconstruction of the cultural attractors as indicated in Table 1 reveals the taxonomy of visual signs (attractors) that are used at the home-page level i.e. to reinforce initial trust formation as part of the wider site UX.

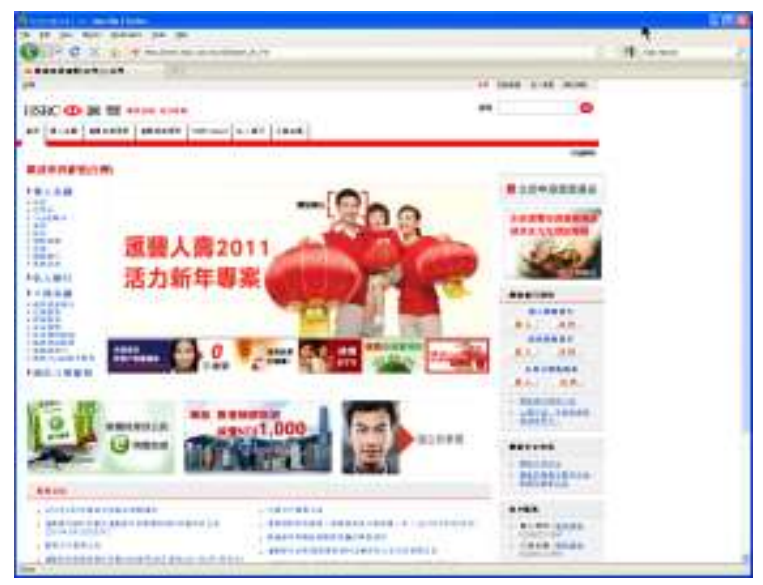

Figure 11. HSBC, Taiwan [3]
Table 2. Sign Taxonomy (HSBC Taiwan E-Banking Site)

\begin{tabular}{|l|l|l|l|}
\hline Signs & $\begin{array}{l}\text { Local } \\
\text { trust } \\
\text { sign? }\end{array}$ & $\begin{array}{l}\text { Global } \\
\text { trust sign? }\end{array}$ & $\begin{array}{l}\text { Visual } \\
\text { impact }\end{array}$ \\
\hline New Year Lanterns & $\mathrm{Y}$ & $\mathrm{N}$ & High \\
\hline Human forms & $\mathrm{Y}$ & $\mathrm{Y}$ & High \\
\hline Promotions 3" party & $\mathrm{Y}$ & $\begin{array}{l}\mathrm{N} \text { (local } \\
\text { only) }\end{array}$ & High \\
\hline $\begin{array}{l}\text { Traditional Mandarin } \\
\text { text }\end{array}$ & $\mathrm{Y}$ & $\begin{array}{l}\mathrm{N} \text { (Simplified } \\
\text { form used } \\
\text { in China) }\end{array}$ & High \\
\hline $\begin{array}{l}\text { "e" brand sign and } \\
\text { pheasant images (Fig. } \\
\text { 12) - implies "green", i.e. } \\
\text { environmental friendly } \\
\text { banking }\end{array}$ & $\mathrm{Y}$ & $\begin{array}{l}\text { Y (when } \\
\text { generalized) }\end{array}$ & Medium \\
\hline $\begin{array}{l}\text { HSBC brand sign } \\
\text { rend }\end{array}$ & $\begin{array}{l}\text { Y (Global } \\
\text { brand) }\end{array}$ & Low/Medium \\
\hline
\end{tabular}

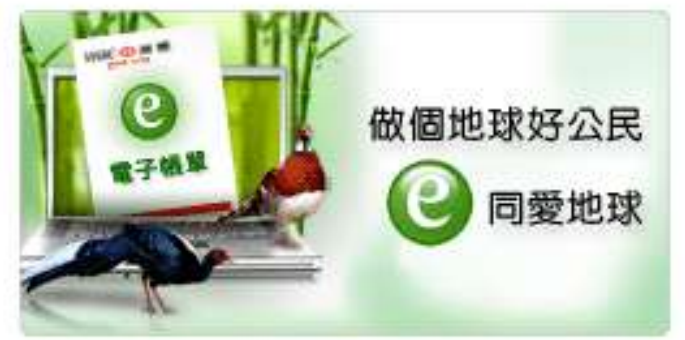

重要登告

， 2011年2月1日基金交易斜止時間通知

Figure 12. 'e' sign on HSBC, Taiwan (Detail of Fig. 11)

From this preliminary (Expert driven) initial examination it would appear that HSBC (being of intrinsically Hong Kong origins) and with a strong Southeast Asian orientation has adopted a more sensitive and successful form of site localization than that adopted by the Deutsche Bank. Both in respect of alignment to Hofstede's cultural dimensions and in respect of the use of visual signs that reflect local norms, a more Taiwanese/Chinese on-line user experience is holistically created.

We freely postulate that this likely leads to the possibility for greater adoption / customer usage of the HSBC sites. Indeed we may even speculate that HSBC's more vibrant localized visual site design may have been produced because the site designers had first hand (instinctive) cultural templates as well as first hand taxonomies of signs with which to work. 


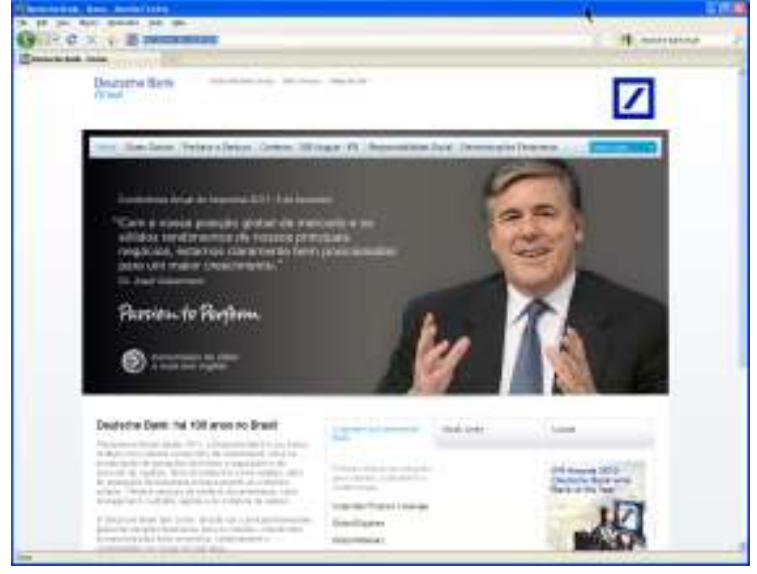

Figure 13. Deutsche Bank, Brazil [3]

This view is reinforced when comparing HSBC and Deutsche Bank sites for other countries. For instance, none of the banks seems to pick up the collectivist culture of Brazil (see Fig. 13 and Fig. 14).

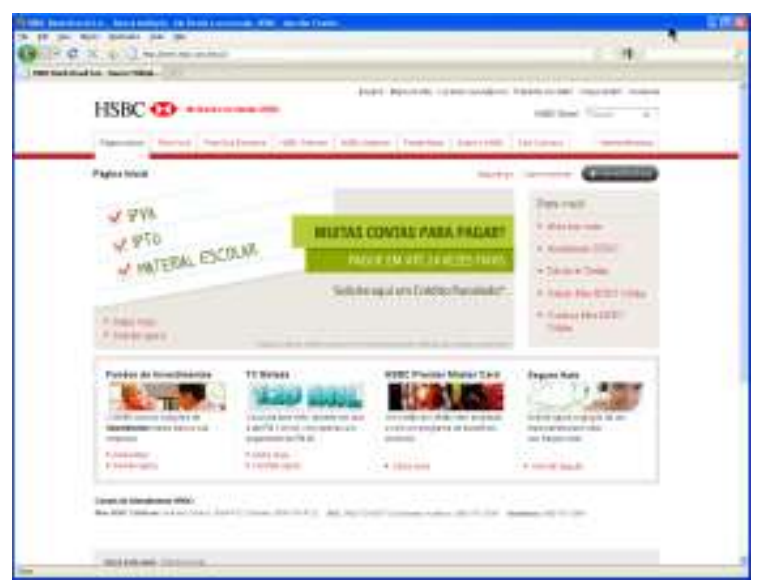

Figure 14. HSBC, Brazil [3]

However, one of the reasons for the Deutsche Bank to adopt a more stereotypical approach for China and Taiwan might be that the Deutsche Bank site is perhaps primarily designed to appeal more to institutional investors rather than local retail customers: hence the prominent use of institutional prominent trusted-buildings visual imagery.

\section{A Card-Sort Driven Approach}

Given the need to instantiate localized sites with local attractors and visual signs designers need a method by which early prototype designs can be selected using a "best of breed" cross-cultural design. Card-sorts are a well established technique in which experimental facilitators seek to probe internal cognitive states by means of eliciting a set of personal constructs. A visual method of card-sorts wherein e-Banking images of home-pages are sorted by users has been shown to be useful in probing UK intangible trust perceptions [12] as well most recently in relation to Nigerian sub-cultural trust perceptions [13]. A "quick-and-dirty" approach is suggested that is designed to leverage card-sorting within normative "quick-time-to-market" industry timescales. That is, we propose that card-sorts are used early on in a system development lifecycle so as to capture intangible trust perceptions (even implicit perceptions that consumers and designers may not be fully able to acknowledge at a conscious level). The rationale is that in so-doing, a better alignment of the HCI component to consumer needs will be achieved upon early release of the product. The idea is as early as possible in an HCI design to capture semi-tacit knowledge from users as follows:

(a) Produce a set of cards that reflect a set of alternative design approaches. These can be manual laminated "cards" or e-cards produced in PowerPoint.

(b) Users sort cards using self-generated constructs.

(c) Individual visual signs on the cards can also be rated by subjects.

(d) From the data gathered a cognitive "map" can be generated showing a rich set of user responses to visual design materials.

(e) Re-design (best-of-breed) takes place accordingly so as to match as far as possible optimal trustworthy designs to target user group.

Further details of the method can be found in [14]. Suffice to say the method implicitly seeks to "go-beyond" coarse grained models such as [15]. Rather, it seeks to validate design materials using a "visual" approach driven by stimulus materials presented to users. Thus it is bottom-up rather than top-down. Others have recently presented leading edge work that also attempts to "go beyond" Hofstede using complimentary techniques such as sentence completion and questionnaires that seek to identify fine-grained cross-cultural visual perceptions of specific icons and images [14].

\section{Validity of Card-Sorting}

One of the advantages of adopting card-sorting is its ability to capture affective trust responses not merely rational. This is important in determining subjects' expectations and as such functions as a probe on emotion as a semiotic phenomenon as part of a user's e-service user experience. For Peirce [16], emotion unites past experience, presence and future expectations. Thus, surface level visual signs embedded within an e-Banking site trigger the formation of emotions in human subjects. These emotions also function as signs. For Peirce, emotions are a legisign - and like any legisign exist through instances or replicas. 
Clearly, individual affective responses to cultural attractors embedded within an e-Banking site may be justified, inappropriate, or disproportionally strong or weak. Such responses unite memory, present, are reflective of current affective state and relate to user goals i.e. future expectations. In this way card-sorts can potentially reveal the role of semiotics as a legisign within a Peircian tradition and the role of emotion as "action as meaning" within in a more behaviouralist Morrission semiotic tradition. Modern techniques derived from neurophysiology mean that affective states can at least in principle be "measured" leading to an exciting possibility that Peircian (or other) theories of emotion can now be tested empirically. In a very real sense therefore card-sorting is a "semiotically" valid investigative technique that can probe semiosis and at a more mundane commercial level can be used at minimal cost to validate or refute the results of the Expert competitor e-Culture site audit in the context of validating early UX site prototypes.

\section{Wider Trust Norms?}

One of the difficulties of interpreting the results of card sorts is to determine the influence of societal level trust perceptions and models upon any given individual's set of responses. Indeed, ideally and as part of future work it will be necessary to try to construct an (e.g. Japanese, Taiwanese, Chinese, etc.) centric trust model expressed as a set of norms and meta-norms so as to be able to contextualize and align consumer devices to wider norms. For example aside for any given HCI design for a mobile phone application such as m-banking it is ideally necessary to probe societal level trust norms.

This kind of trust modeling at the societal hence organizational level might well seek to explain why for example the Japanese are in "love" with mobile devices as mediators for much of their urban lives, whilst in the UK users are much less willing (so far!) to use mobiles in such a ubiquitous manner. Previous work has shown that deontic logic can be used to articulate norms and it is now possible that trust / policing agents may be developed in the future to monitor how well a particular application matches such norms [17].

To give a purely anecdotal (amusing) example, here is a Japan / Southeast Asian culturally specific norm framed using deontic logic:

$<$ Whenever> my son/daughter makes their (online) diary entry I have a parental <obligation> to read all their diary entries (as their mother / father etc.) I am most certainly <permitted> to ask my son/daughter for their password as necessary to carry out this parental duty until they marry [...]

Without attempting to probe all the family related trust relationships implied by the above example it can be seen immediately by UK readers that this particular parent-child norm would not easily translate to a UK context of familial relationship harmony! An overview and further details of deontic logic for norm specifications can be found in [3].

\section{Conclusion}

Intangible consumer trust perceptions are clearly relevant to device or application adoption and form part of a user's experience. It has been suggested (and pilot studies have shown that) card-sorts may be useful in capturing intangible trust requirements in a cross cultural context. However, without also building a detailed "Eastern" specific model of trust relations as they are seen to operate within homecontexts of use (e.g. families) within security and privacy norms (e.g. mobile banking) and even wider as part of notions of social capital, it will be difficult to fully interpret the findings of card-sorts. This is even more the case for places that do not so easily fall into the 'Western' or 'Eastern' category, as shown on the examples of Zanzibar or Brazil.

This paper seeks to suggest that an expert site audit of existing competitor e-Culture specific sites can help to establish a normative e-Culture visual shopping experience that is specific to any given target audience. Later it is suggested that card-sorts "may" also prove to be useful in software localization contexts. However, we also seek to highlight the need for the building of rich and subtle trust models that fully reflect the fundamental and subtle differences that certainly exist as between Taiwanese, Chinese and UK consumers. These needs cannot be fully anticipated without reference to norms based trust models. These models once validated, could be used to enable software agents to dynamically adapt HCI and more generally HCI based products to users on either side of the cultural divide.

This paper is essentially a call for further active research in the area of intangible trust modelling as well as a call for empirical studies in "West/East" culturally specific contexts. Anecdotally, in a recent industry study it was seen that to carry out a "homestudy" of a consumer device Western facilitators needed to enter Japanese Homes [18]. This raised a number of relevant trust issues that were not fully anticipated prior to the study. Had these issues been modeled and understood, more reliable study results may have been achieved. For example anecdotally, Japanese subjects were very reluctant to admit researchers into their home at all, and when they did so they were equally reticent in providing feedback. These reactions were due to the very "private" sense of the home in contrast to western notions.

Mainly, such barriers as these are due to a fundamentally different role of the home and family as part of society. Without probing trust, existing "Western" HCI methods may indeed be 
compromised when migrating to a Southeast Asian localization context. Thus, a greater and deeper understanding of trust issues (in general) is needed and indeed an issue of much broader cultural concern than merely a consideration of card-sorting and norms suggested by this paper. These are merely some candidate tools that may or may not prove fruitful in fostering greater mutual understanding in relation to aligning consumer needs to devices and applications.

Therefore we propose the use of Expert heuristic evaluation of existing competitor sites followed by early adoption of card-sorts by reliable witnesses prior to any detailed in situ cross-cultural investigation. This approach will help to fast-track cross-cultural design at minimal cost and help to reduce the downstream costs associated with in situ usability studies, focus groups that of necessity need to be carried out in target countries/cultures.

\section{Acknowledgements}

The authors would like to thanks the Office of Second Vice President of Zanzibar for permission to do this research in Zanzibar, and the State University of Zanzibar and the World Bank for funding.

\section{References}

[1] French, T, "Towards an E-Trust Framework," Doctoral Thesis. Department of Systems Engineering, University of Reading, UK, 2009.

[2] H. T. Keh and Y. Xie, "Corporate reputation and customer behavioral intentions: The roles of trust, identification and commitment," Industrial Marketing Management Journal, Vol. 38, 7, 2009, pp. 732-742.

[3] K. Liu, Semiotics in Information Systems Engineering, Cambridge University Press, 2000.

[4] R. Stamper, K. Liu, M. Hafkamp and Y. Ades, 'Understanding the roles of signs and norms in organisations', Journal of Behaviour \& Information Technology, 19(1), pp. 15-27, 2000.

[5] R. Stamper Information in business and administrative systems. New York: John Wiley and Sons, 1973.

[6] M. Gottdiener, Postmodern semiotics: material culture and the forms of postmodern life, Oxford: Blackwell Publishers. 1995.

[7] G. Hofstede, Culture's consequences: comparing values, behaviors, institutions and organizations across nations. 2nd Ed. Thousand Oaks, Calif: SAGE Publications, 2001.

[8] I, Vander Biesen, "Social and Intercultural Relations in Nineteenth-Century Zanzibar: Dressed Identity," African and Asian Studies, 8(3), pp. 309-331, 2009.

[9] T. Asai, A.U. Hakizabera, "Human-related problems of information security in East African cross-cultural environments", Information Management \& Computer Security, Vol. 18 Iss: 5, pp.328 - 338, 2010.
[10] A. Sultani, 'Zanzibar to adopt e-government 2012', Daily News. [Online] Available at: http://dailynews.co.tz/business/?n=24431. (Accessed: 20 October 2011).

[11] M. Conrad and T. French, "Hofstede's cultural dimensions and web sites of banks," (online), 2011, available at: http://perisic.com/cu

[12] T. French and M Spingett, "A Card-Sorting Probe of EBanking Perceptions," procs. HCI 2007, Lancaster University, BCS Press, 2007, pp. 45-53.

[13] T. French and K. Opatola, "A Pilot Investigation of EBanking trust perceptions amongst the Yoruba and Igbo of Nigeria," procs. IWIPS 2010, Product and Systems Int., Press Ltd., 2010, 107-116.

[14] E. Knight, C. Gunnarwardena and E. Barbera, "Beyond Hofstede: Designing Visual Meanings of Icons and Images for Cross-Cultural Interpretation," procs. IWIPS 2010, Product and Systems Int., Press Ltd., 2010, pp. 163-166.

[15] G. Hofstede, Cultures and Organisations: Software of the Mind. New York: Mc Graw-Hil. 2001.

[16] D. Savan, "Peirce's Semiotic Theory of Emotions," procs. C.S. Peirce Bicentennial Conference, Amsterdam, June 1976, edited by K. Ketner et. al. Lubbock: Texas Tech. University Press, 1981.

[17] M. Chan, "Design of a Modelling Language for Semiotics Based Agent Systems," Procs. of the 12th International Conference on Informatics and Semiotics in Organisations, Reading University, UK, 2010, pp. 95-110.

[18] T. French, K. Rambo and A. Kupper, "Culture and Trust in Online Applications: Does cultural variation affect the making of trust? Break-out session," procs. IWIPS 2010, Product and Systems Int., Press Ltd., 2010, pp. 191-192 